\title{
TUBULIN TARGETED ANTIMITOTIC AGENTS BASED ON ADAMANTANE-BEARING LEAD-COMPOUND: SYNTHESIS, SAR AND MOLECULAR MODELING
}

\author{
N. Zefirov ${ }^{1,2}$, Y. Evteeva', A. Krasnoperova', A. Mamaeva', E. Milaeva ${ }^{1,2}$, \\ S. Kuznetsov ${ }^{3}$ and O. Zefirova ${ }^{1,2}$ \\ ${ }^{1}$ Department of Chemistry, M.V. Lomonosov Moscow State University, \\ 119992 Russia, Moscow, Leninskie gory, $1 / 3$. \\ ${ }^{2}$ Institute of Physiologically Active Compounds, Russian Academy of Sciences, \\ 142432 Russia, Chernogolovka, Severny pr., 1. \\ ${ }^{3}$ Institute of Biological Sciences, University of Rostock, \\ D-18059 Rostock, Germany, Albert-Einstein-Str., 3.
}

DOI: 10.19163/MedChemRussia2021-2021-407

E-mail:57anna75@mail.ru

Adamantyl moiety is occasionally used in drug design for enhancement of lipophilicity or bulkiness of the lead molecule. Such modification can improve both pharmacokinetic properties and toxicological profile of the compound, which is especially important for anticancer drugs. Anticancer agents comprising adamantyl moiety belong mostly to DNA-cross-linking agents, inhibitors of protein tyrosine kinases and ligands of retinoic acid receptors [1]. Recently we designed a novel antimitotic agent, namely 5-hydroxymethyl-2-methoxyphenyl adamantane-1-acetate (1, Figure 1$)$ and proved its ability to stimulate depolymerization of microtubules (MTs) [2]. The structure of compound 1 is not typical for the tubulin and MTs ligands, so in this work we synthesized and tested a series of its analogs. Lead 1 comprises three substructures: adamantane, the substituted aromatic ring and the linker, which were sequentially modified in the work (Figure 1).

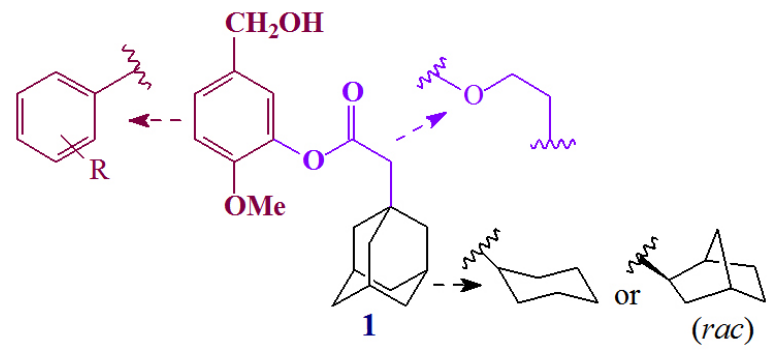

Fig. 1. Structure of the lead compound 1 and its modifications carried out in the work.

The structure - activity relationship (SAR) studies led to the discovery of 1-[2-(5-(hydroxymethyl)-2-methoxyphenyl)ethyl]adamantane, which exhibits a dual-target profile and retains in vitro activity observed for the lead-compound, but is more stable metabolically.

The work was supported by Russian Science Foundation (project 19-13-00084).

\section{References}

[1] L. Wanka, Kh. Iqbal, P. R. Schreiner, Chem. Rev., 2013, 113, 3516.

[2] N. A. Zefirov, E. V. Nurieva, Yu. A. Pikulina et al. Russ. Chem. Bull., Int. Ed., 2017, 66, 1503.

[3] N. A. Zefirov, Y. A. Evteeva, A. I. Krasnoperova, A. V. Mamaeva, E. R. Milaeva, S. A. Kuznetsov, O, N. Zefirova. Mendeleev Commun., 2020, 30, 421.

$$
-407-
$$

